\title{
Sex Work and Occupational Homicide: Analysis of a U.K. Murder Database
}

\section{Stewart Cunningham', Teela Sanders', Lucy Platt², Pippa Grenfell2, and P.G. Macioti ${ }^{2}$}

\begin{abstract}
This article presents an analysis of occupational homicides of sex workers in the United Kingdom, 1990-2016. Characteristics of IIO people murdered between 1990 and 2016 are explored including the location of their murder, ethnicity, migration status, and gender. Key changes over time are noted including an increase in the number of sex workers murdered indoors as well as an increase in murdered migrant sex workers. By developing the concept of "occupational homicide," we argue that sex worker homicide should be viewed as an occupational issue and that the distinction between work-related homicide and nonwork-related homicide should be accounted for in future studies and is essential to inform prostitution policy.
\end{abstract}

\section{Keywords}

sex work, prostitution, murder, work-based homicide, occupational homicide, serial killer

\section{Introduction}

In the literature on sex work and homicide, a consistent theme is the extraordinarily high risk of murder faced by those who sell sex. It has been estimated that cis-gendered female sex workers in the United States are 18 times more likely to be murdered than women of the same age and race from the general population (Potterat et al., 2004, p. 782) and are often targeted by serial offenders (Quinet, 2011). ${ }^{1}$ In a U.K.-based study of sex workers in London, cis-gendered female sex workers' mortality rate was recorded

\footnotetext{
'University of Leicester, UK

${ }^{2}$ London School of Hygiene \& Tropical Medicine, UK

Corresponding Author:

Teela Sanders, Department of Criminology, University of Leicester, 154 Upper New Walk, Leicester, Leicestershire LEI7QA, UK.

Email: Teela.sanders@leicester.ac.uk
} 
as 12 times higher than women from the general population and murder was identified as one of the leading causes of death (Ward, Day, \& Weber, 1999, p. 342).

This article will review the existing literature on sex work-related murder, from North America and the United Kingdom, with a more detailed focus on the United Kingdom. Findings from our own database of sex worker murders in the United Kingdom occurring between 1990 and 2016 will also be presented.

\section{Sex Work Laws in the United Kingdom and the United States}

As this article focuses on the U.K. context, it is important to first set out the country's legal approach to sex work. First, it is not a crime for two consenting adults to sell or pay for sex. However, there are many laws (often dating back to the 1950s) relating to how sex is bought and sold, that make it a quasi-legal (or quasi-criminal) activity. There are soliciting, kerbcrawling, and various nuisance-related offenses that can be used against both clients and sex workers on the street (Feis-Bryce, 2018). In terms of indoor sex work, brothel-keeping laws make it illegal for two or more sex workers to share premises, and third parties (such as receptionists, drivers, security) can be criminalized through procuring laws and laws against living off the earnings of prostitution. Hence, the law means that much of the sex industry remains shrouded in secrecy, and there is evidence of reduced legal consciousness among many sex workers as the law is so complex and confusing (Graham, 2017; Klambauer, 2017). Yet many people circumvent these laws by working as independent escorts, advertising a range of services (focused on time and not sexual services) through a multitude of digital spaces and methods (Sanders, Scoular, Campbell, Pitcher, \& Cunningham, 2018).

The quasi-legal situation in the United Kingdom, which pushes the sex industry into the informal economy and away from any mode of regulation, can be compared to the laws in the United States, which are predominantly examples of full criminalization. Aside from the legalized brothels of Nevada (Brents, Jackson, \& Hausbeck, 2010), and despite the federal state system, which gives states freedom to set their own laws, the general approach across the United States is that buying and selling/organizing commercial sex is illegal. Like in the United Kingdom, there are often a host of laws which also criminalize the activities around the selling of sex: pandering, procuring, promoting prostitution, solicitation, or agreeing to engage as a seller or buyer. However, the differences are most likely in the enforcement of the laws, as the United States appears to be stringent in their efforts to arrest, prosecute, and imprison whereas the United Kingdom approaches range from enforcement (fines not prison) to harm reduction and welfare/protection approaches including the first managed street sex work zone (see Sanders \& Laing, 2018).

\section{Method}

\section{U.K. Sex Worker Murder Database}

We analyzed a database of known murders of sex workers occurring in the United Kingdom from 1990 to 2016 . The database was started by grassroots practitioners in 
1990 and then handed over to the National Ugly Mugs (NUM) in 2010, an organization that receives and disseminates alerts about dangerous and violent clients in the United Kingdom. The database is compiled primarily through on the ground knowledge of sex worker murder with data provided by sex work support projects, from police reports, and supplemented by information available in the media. The database records information on the sex working victim (their name, age, type of sex work undertaken, where killed), the perpetrator (name, relationships to victim, charges brought, outcome of case, and sentencing) as well as some basic information on the circumstances of the murder, for example, method of killing. While we cannot say with certainty that our database constitutes a record of absolutely all sex worker homicide in the United Kingdom, in the absence of a comprehensive police database, we believe that it is likely to be the most accurate existing resource on the subject given its proximity to the sex worker community and those with on the ground knowledge. The Homicide Index, for example, recorded 17 sex worker homicides in England and Wales between 1995 and 1999 (Brookman \& Maguire, 2003, p. 38) while our database has 26 cases recorded during the same period. ${ }^{2}$ Also to validate our database as being the most comprehensive, we noted that for the same time period used for the Salfati, James, and Ferguson study (hereafter the Salfati study) (2008), which included 54 incidents of sex worker murders, we have 80 incidents recorded in our database.

According to our database, there were 180 sex workers murdered in the United Kingdom between 1990 and 2016. We reviewed the contents of this database and cross-referenced it against other available sources, predominantly local and national media, where information was missing. We identified 110 of the homicides in the database as being directly work related (occupational) because the sex worker was killed either by a client, in a sex working workplace, or last seen alive in a known street sex work area. Thirty-seven of the homicides we classed as nonwork related as the perpetrators were family members, partners, or friends of the victim. Thirty-three of the homicides we were unable to classify in this way because of lack of information. There is no separate source of data on the number of missing sex workers during this period although in some instances the victims in our database were never found and so are missing, presumed murdered.

\section{Existing Literature on Sex Worker Homicide}

\section{Extent and Prevalence of Sex Worker Homicide}

The most widely referenced statistic on the risk of homicide faced by sex working women concludes that they are 18 times more likely to be murdered than women of a similar age and race (Potterat et al., 2004, p. 782). This finding was part of a wider study on the mortality of sex workers based on a large sample $(n=1,969)$ of sex working women from the Colorado Springs area in the United States. The researchers used two separate cohorts of women for calculating mortality rates, devising a cumulative cohort and then an active or moving cohort. ${ }^{3}$ The researchers calculated the expected number of deaths using "sex-,age-, and race-specific mortality tables" both for all causes of death and then homicide separately (Potterat et al., 2004, p. 780), then 
compared the expected number of deaths to the actual number of deaths (and homicides) in their cohorts to establish mortality rates.

Potterat et al., 2004 calculate a standardized mortality rate for women in the cumulative cohort of 1.9 (95\% confidence interval [CI] $[1.5,2.3])$ and in the active cohort of $5.9(95 \%$ CI $[3.2,9.0])$ (pp. 780-781). The risk of mortality for all women in the study was, therefore, 2 times greater than for other women of a similar age and race (Potterat et al., 2004, p. 780). While they were actively working as sex workers, the risk of mortality rose to almost 6 times greater than that faced by nonsex working women. Looking more closely at homicide, Potterat et al., conclude that in the cumulative cohort sex working women were almost 8 times more likely to be murdered and in the active cohort this increased to almost 18 times (Potterat et al., 2004, pp. 781782). Standardized homicide mortality rates are 7.9 (95\% CI $[4.5,11.3])$ for the cumulative cohort and 17.7 (95\% CI $[6.2,29.3])$ for the active cohort (Potterat et al., 2004, p. 782).

The methodology used to calculate these mortality rates can, however, be critiqued based on the study's sampling method. Researching sex workers, a so-called "hidden" or "hard to reach" population, is notoriously difficult and obtaining a representative sample is extremely challenging (see, for example, Heckathorn, 1997; Magnani, Sabin, Saidel, \& Heckathorn, 2005). Potterat et al. gathered their data from police and health department records as well as from women who voluntarily presented themselves at sexual health, HIV, and drug treatment clinics. It is reported that the authorities in Colorado Springs operated a policy of "enhanced monitoring" of women involved in prostitution from the 1960s including a mechanism whereby arrested sex workers were ordered to undergo sexual health testing (Potterat et al., 2004, p. 779). Such police actions and related data monitoring would have influenced the representative sampling strategy, as it would have been mainly arrested sex workers in the sample.

Lowman and Fraser (1994) reached a significantly higher estimate on the homicide rate of sex workers in Vancouver, British Columbia (BC), based on homicide data and an estimation of the female street sex work population from 1990. They concluded (albeit tentatively) that the murder rate for adult women involved in street prostitution in Vancouver was between 112 to 225 per 100,000, which is 60 to 120 times higher than the rate at which women from the general population were murdered (Lowman \& Fraser, 1994, p. 43).

No attempt has been made to calculate a homicide mortality rate for sex workers in the United Kingdom, but in research by Ward et al. (1999, p. 342) they conclude that the women in prostitution recruited to their study had a general mortality rate 12 times greater than non-sex working women aged 15 to 44 in Greater London (mortality rate is $12.15 ; 95 \%$ CI $[4.6,32.4])$. This study included women working in all sectors of the industry (Ward et al., 1999, p. 340). Four women died during the study, two of whom had been murdered - one woman was killed by her boyfriend and the other woman's murder remains unsolved. The researchers note that "these women were at no obvious risk of violent death; both worked through referral and avoided public soliciting; neither injected drugs" (Ward et al., 1999, p. 342). Although Ward, Day, and Weber did 
not calculate homicide mortality rates, we know that $50 \%$ of the women in their study who died were murdered. This is exactly the same percentage of homicides from the total number of deaths in Potterat et al.'s active cohort. Given that the general mortality rate established by Ward, Day, and Weber was 12, twice as high as the 5.9 for Potterat et al.'s active cohort, this may suggest that the homicide mortality rate for the sex workers in Ward, Day, and Weber's study could be as high as 36.

Shifting the focus to occupational murder. Potterat et al. maintain that out of the nine women killed in the active cohort of sex workers, eight were "murdered on the job" and they do conclude that "the vast majority of murdered women in our sample were killed as a direct consequence of prostitution" (Potterat et al., 2004, p. 782). The calculation of the risk of homicide was, however, completed using all murders, whether they occurred in the course of working or in other circumstances. In an initial analysis of sex worker homicide in the United Kingdom by Kinnell, she also did not separate out murders committed during the course of work, although did include an analysis of the location where sex workers were killed which shows whether individuals were working on the street, indoors alone, or indoors collectively (Kinnell, 2008, p. 176). We believe that this oversight to distinguish between work-related homicide from homicide occurring in other circumstances to be a weakness of the existing literature. Making these distinctions and identifying homicides that are specifically work related will enable a more productive assessment of the conditions in which sex work is undertaken that may make sex workers more vulnerable to homicide. We argue that sex worker homicide should be viewed as an occupational issue and that the distinction between work-related homicide and nonwork-related homicide should be accounted for in future studies and is essential to inform prostitution policy.

Sex workers, like all other people, experience violence and harm in different contexts, including related to their work and circumstances not related to their work. While the circumstances of a sex worker's homicide do not make it any more or less troubling, we believe that the issues presented by different forms of homicide require different analyses and distinct responses. As a result, we have classified the murders in our database into work-related murders and nonwork-related murders. We classify a murder as work related if the perpetrator was known to have approached the victim as a client, the sex worker was killed in a sex industry workplace, or was picked up by their killer in a known red light area. If the murder was unsolved but the victim was last seen working in an area known for soliciting, then we classified this as work related. If no information was known at all about the circumstances of the murder, including where the killer met the victim, because it remained unsolved, then we classified this as "not known."

For our classification purposes, murders that were committed by friends, acquaintances, and family members or in other circumstances unrelated to the victim's involvement in sex work were classified as nonwork related. It has been established though in nonsex work studies that murders can still take place in the workplace but be committed by family members: $33 \%$ of workplace homicides against women in the United States (between 2003 and 2008) were committed by a personal relation, the 
majority (78\%) being intimate partners (Tiesman, Gurka, Konda, Coben, \& Amandus, 2012). While these are classed as examples of both workplace homicide and intimate partner violence, we argue that our classification of sex worker homicides committed by family members as nonwork related is valid as it enables a focus on the occupational factors that make sex workers so vulnerable to homicide at the hands of strangers and clients, who represent the majority of perpetrators (Brewer et al., 2006; Neville, 2012; Salfati, 2008).

\section{Sex Worker Homicide in the United Kingdom}

Existing knowledge on sex worker homicide in the United Kingdom has been produced by two key scholars, Kinnell and Salfati, and these studies together provide us with data analysis up until 2006. Hilary Kinnell foregrounded the academic examination of violence and murder against sex workers based largely on her many years as a leading practitioner in the United Kingdom. ${ }^{4}$ In her book Violence and Sex Work in Britain (Kinnell, 2008), some of the concluding comments are particularly helpful, especially when tracking trends in sex worker homicide as this article intends. Kinnell concludes based on the analysis of the same database we have (from 1990-2006) that "It is absolutely clear that sex workers risk of homicide is primarily determined by location and isolation when engaging in sex work, with street soliciting the most obvious risk factor, and working indoors but alone the next most risky environment" (2008, p. 178). This has been a useful place to start when trying to understand the current picture with regard to sex worker homicide in the United Kingdom.

Building on the work of Kinnell, there is only one published article, the Salfati study (2008), addressing the issue of sex worker homicide in the United Kingdom. This study compares a data set of sex worker homicides with data sets on sexual homicides and nonsexual homicides (all with female victims) with the intention to determine why sex workers are more susceptible to fatal violent attack than other women. The data set on sex worker homicides used by the Salfati study was compiled from information provided by the U.K. Home Office, press reports compiled by Hilary Kinnell, and information provided from various police forces. It covers the period January 1990 to April 2001, and from a total number of 54 cases the researchers selected 46 for inclusion in their analysis (Salfati, 2008, p. 520). The comparator cases (sexual homicides and nonsexual homicides) were selected from an existing homicide database compiled by Salfati (2008, pp. 520-521).

Neville (2012), in her unpublished dissertation study, also conducted a comparative study on sex worker homicide in the United Kingdom. Neville obtained her data on sex worker homicide from the closed case files from a number of police forces across the United Kingdom and examined 92 cases of sex workers murdered in the United Kingdom between January 1980 and December 2005 (Neville, 2012, pp. 115-116). In all, $63 \%$ of these cases were solved and $37 \%$ unsolved (Neville, 2012, p. 116). In addition to the case files, she supplemented her data through interviews with senior investigating officers in 10 of the cases. Her criteria for inclusion were that the victim was female, she had been actively sex working at the time of her death, and her body had 
Table I. Victim Demographics, Sex Worker Occupational Homicide, United Kingdom, 1990 to 2016.

\begin{tabular}{|c|c|c|c|c|c|c|}
\hline \multirow{2}{*}{$\begin{array}{l}\text { Demographic } \\
\text { indicators } \\
\text { Gender } \\
(n=110)\end{array}$} & \multicolumn{6}{|c|}{ Victim characteristics } \\
\hline & $\begin{array}{r}\text { Cis-gendered } \\
95.5 \%\end{array}$ & $\begin{array}{l}\text { d woman } \\
(n=105)\end{array}$ & $\begin{array}{r}\text { Cis-gendere } \\
1.8 \%(\end{array}$ & $\begin{array}{l}d \text { man } \\
(n=2)\end{array}$ & $\begin{array}{r}\text { Trans wom } \\
2.7 \%(\end{array}$ & $\begin{array}{l}\operatorname{lan} \\
(n=3)\end{array}$ \\
\hline \multirow[t]{2}{*}{$\begin{array}{l}\text { Work sector } \\
\qquad(n=109)\end{array}$} & Street & & $\begin{array}{l}\text { Indoors (ind } \\
\text { private flat }\end{array}$ & $\begin{array}{l}\text { Jependent/ } \\
\text { t) }\end{array}$ & Indoors (br & othel) \\
\hline & $78 \%($ & $(n=85)$ & $19 \%(n$ & $n=2 I)$ & $3 \%(n$ & $=3)$ \\
\hline \multirow[t]{2}{*}{$\begin{array}{l}\text { Ethnicity } \\
\qquad(n=100)\end{array}$} & $\begin{array}{l}\text { White } \\
\text { British }\end{array}$ & $\begin{array}{l}\text { White Eastern } \\
\text { European }\end{array}$ & Mixed race & Black $^{\mathrm{a}}$ & Asian $^{\mathrm{a}}$ & Other \\
\hline & $77 \%(n=77)$ & $9 \%(n=9)$ & $6 \%(n=6)$ & $5 \%(n=5)$ & $2 \%(n=2)$ & $\mathrm{I} \%(n=1)$ \\
\hline $\begin{array}{l}\text { Migration status } \\
(n=98)\end{array}$ & \multicolumn{2}{|c|}{$\begin{array}{l}\text { British born } \\
87 \%(n=85)\end{array}$} & \multicolumn{4}{|c|}{$\begin{array}{l}\text { Migration background } \\
13 \%(n=13)\end{array}$} \\
\hline
\end{tabular}

aGiven the low numbers of Black and Asian sex workers in the database, we chose not to subdivide these ethnic groups as they are recorded in the U.K. census, for example, Black African, Black Caribbean, and so on.

been found (Neville, 2012, p. 117). Neville's comparative sample consisted of 89 case files obtained from the Metropolitan Police of nonsex working women murdered in Greater London between January 2000 and December 2006 (Neville, 2012, p. 168). Inclusion criteria were that the victim was female with no known history of prostitution, aged 15 or over, that her body had been found, and that the offender was male (Neville, 2012). A significantly higher percentage of the comparator cases (98\%) were solved.

\section{Victim Demographics}

Gender. All of the existing literature on sex worker homicide focuses predominantly on the murder of cis-gendered female sex workers and as noted in Table 1 the vast majority $(95.5 \%, n=105)$ of victims of occupational homicide in our database were cis-gendered women. The focus in the literature on cis-women, at least in a U.K. context, is, therefore, understandable.

Work sector. The Salfati study only looked at the murders of women who worked on the streets (2008, p. 520) whereas work sector was more diverse in Neville's sample. The majority of the women in Neville's sample did work on the street $(67.4 \%)$ but $18.5 \%$ were described as "self-employed call girls," $6.5 \%$ were agency workers, $4.3 \%$ were brothel/sauna workers, and 3.3\% were classified as "other" including "people who exchanged sex for drugs/food/shelter on an ad hoc basis" (2012, p. 123). This pattern was reflected in our sample with the majority of victims working on the street (78\%, $n=85$ ) with indoor workers (mostly independents working from their own or shared flats) the next largest group $(19 \%, n=21$; see Table 1). The trans women and 
male sex workers, in our database, were all independents working from their own homes when they were killed. Interestingly, Neville notes that there was no significant difference in the solve rate for the murder of street working women as opposed to women working in other sectors in her sample, "indicating that the degree of challenge that prostitute homicides pose for police investigations is similar regardless of the working conditions of the victim" (Salfati, 2008, pp. 124-125).

Analysis of our database also shows that a shift has taken place in the United Kingdom, and since 2010 more sex workers have been killed in indoor workplaces than on the street. Between 1990 and 1999, 85\% $(n=28)$ of sex work occupational homicide was committed against street-based sex workers. The overall numbers of homicides increased significantly in 2000 to 2009, but the percentage of street-based victims remained the same at $85 \%(n=50)$. Between 2010 and 2016, however, this pattern has reversed and there are now more indoor sex workers killed $(59 \%, n=10)$ than street-based sex workers $(41 \%, n=7)$. This could potentially reflect the changing working practices for sex workers with the rise of Internet facilitated indoor working coincides with a significant decline in street-based sex working (Sanders et al., 2018)

Ethnicity and migration status. The ethnicity and migration status of victims was not addressed by Salfati et al., but Neville (2012, p. 122) notes that $86 \%$ of her sample were British and the other $14 \%$ were of various nationalities. The majority of her sample $(79 \%, n=73)$ were White (Neville, 2012). Analysis of the NUM database also shows that the vast majority of sex workers killed, where ethnicity was known, was of White British ethnic background (see Table 1). We were also able to ascertain whether the sex worker was British born or a migrant in 98 cases (see Table 1) and also found that migrant sex workers' vulnerability to homicide has increased in recent years.

In the 20 years between 1990 and 1999, only 6\% $(n=5)$ of sex work occupational homicide victims (where nationality/migration status is known) were migrant sex workers compared to $94 \%(n=77)$ who were British born. Since 2010 , the percentage of migrant sex workers killed has dramatically increased to $50 \%(n=8)$, exactly the same number of British born victims. This could potentially reflect changes in the overall makeup of the sex industry in the United Kingdom with increasing numbers of migrant workers (Mai, 2009) and/or suggest that offenders are specifically targeting migrants because of their potentially increased vulnerability.

Other victim characteristics. The NUM database has not been compiled from detailed police case files and as a result only records basic demographic information of the victims like gender, ethnicity, geographical location, and nationality/migration status. Sometimes a victim's drug use was recorded in the database, but this information is sporadic and given the lack of consistency we are unable to include drug use in our analysis. We note that a much wider range of victim characteristics (e.g., living situation, parental status, relationship status etc.) were explored in the Salfati study (2008) but given that our focus is restricted more to examining sex worker homicide as a form of work-related murder, we do not believe that an analysis of these additional victim demographics is necessary in our article. We do not attempt to reach any conclusions 
on factors that may make sex workers vulnerable to murder beyond their work setting (street, indoors, etc.), gender, and their migration status.

Offender characteristics. While our database does not record any demographic information on the offenders beyond their name (in solved cases), it is worth making three observations from the information we have about the following: (a) conviction rates, (b) perpetrators, and (c) serial killers. First, we have information about the outcome of the criminal trials where charges were laid against an alleged perpetrator. Conviction data show that between 1990 and 2016, 59 homicide convictions were achieved in situations of sex worker occupational homicide (this does not include cases where charges were brought for culpable homicide or manslaughter). It is worth noting that the solve rate for work-related homicide has improved substantially during the relevant time period with every single case in our database from 2006 being solved compared to the 1990s and early 2000s when high numbers of cases remained unsolved. Sentencing data show that the average prison term has increased over the period, with notably longer sentences from 2004 onward. From 2010, more whole life tariffs have been issued and the average minimum prison sentence imposed on those convicted of the murder of a sex worker is 22.75 years.

Second, although we have no characteristic data on the perpetrators, as we have accounted for those murdered by partners or family, the assumption is that most of the 110 sex workers murdered in the course of their work were killed by either a stranger apprehending the sex worker on the street, or more likely a stranger client (or possibly a client that they had seen on previous occasions). This collaborates with analysis from other studies. Neville (2012) notes that $51.7 \%(n=30)$ of the 58 solved cases in her sample were committed by a "stranger/client" and a further $15.5 \%(n=9)$ were committed by a regular client (p. 130).

Our assumption in relation to clients as the main suspect/perpetrator is also confirmed by the analysis from Kinnell (2008, p. 18) who found that $65 \%(n=57 / 88)$ of suspects had a client relationship to the victim. The Salfati study found that the offender was a stranger in $54.2 \%(n=13)$ of the 24 cases where this information was available (2008, p. 529). It is, however, worth noting that both studies concluded (albeit tentatively) that there are differences between those who murder sex workers and the general client population. Perhaps most significant is the high level of previous convictions (for both violent and nonviolent offenses) among the homicide offenders compared to the general client population (Neville, 2012, p. 135; Salfati et al., 2008, p. 530).

Third, we are aware from the NUM database that 17 sex workers were killed by serial offenders in the United Kingdom between 1990 and 2016. We define serial offenders as any offender killing more than one person in separate incidents. The actual figure of sex working serial murder victims may be higher as there are suspicions that some of these men are responsible for some of the remaining unsolved sex worker murders. All of the murders by serial offenders occurred in the course of the victim's work. We calculated that the percentage of sex working occupational homicide victims who were killed by serial perpetrators was $15 \%$ of all solved cases, much 
lower than results from the United States with Brewer et al. (2006, p. 1106), for example, concluding that $35 \%$ of sex worker homicide victims in the United States between 1982 and 2000 were killed by serial perpetrators. Some of the serial offenders in the United Kingdom were known only to have targeted sex workers and others had both sex working and nonsex working victims. In the United Kingdom, the history of serial killers targeting those in the sex industry has a dark past, largely related to the Peter Sutcliffe case, a serial killer who committed (at least 13) homicides against women, some sex workers, between 1975 and 1980 (see Kinnell, 2008, Chapter 1).

\section{Occupational Homicide: Sex Worker Murders in Context}

In the period 1993 to 2002, which saw an overall decline in rates of workplace homicide in the United States (in line with a decline in all homicide), the occupations with the highest rates were taxicab drivers $(46.1$ per 100,000), (private) taxicab drivers and chauffeurs (23.7 per 100,000), and liquor store workers (12.0 per 100,000; Hendricks, Jenkins, \& Anderson, 2007, p. 321). ${ }^{5}$ The rates on occupational homicide in this study were not, however, by gender but we can assume that these victims are mainly male as these jobs are male dominated. In earlier studies, using data from the 1980s on female occupational mortality in the United States, the retail and service sectors were identified as the industries with the highest rates of occupational homicide for women (Bell, 1991; Davis, Honchar, \& Suarez, 1987; Jenkins, 1996; Levin, Hewitt, \& Misner, 1996).

Rates of occupational homicide in the United States, broken down by job type, are published annually by the U.S. Department of Labor. No such data source exists in the United Kingdom. We were able to identify two sources of data that provided some, very limited, information on occupational homicide in the United Kingdom. The first was a wider study of occupational mortality in England and Wales, covering the period 1992 to 2000, published by the Office for National Statistics (ONS) and Health and Safety Executive (HSE; Coggon, Harris, Brown, Rice, \& Palmer, 2009). The study analyzed "all deaths in England and Wales during 1991-2000 at ages 16-74 years" through data extracted from death certificates, including the "sex, age at death, underlying cause of death and last full-time occupation of the deceased" (Coggon et al., 2009 , p. 6). Homicide, as a cause of mortality, was addressed and the study identifies any occupation where the Proportional Mortality Rate (PMR) for homicide was "higher than 120" and therefore "statistically significant" (Coggon et al., 2009, p. 16). PMRs on homicide (as for all other causes of death) were calculated by multiplying the total number of deaths in each specific job group with the proportion of all homicides across all job groups, which establishes the expected number of homicides in each job group. This was then compared to the actual number of homicides in the job groups and a percentage was calculated representing the PMR.

The two occupations with the highest PMRs for women workers were "publicans and bar staff" and "caterers" (Coggon et al., 2009, p. 36). Both of these occupations had a PMR of 193, which corresponded to 16 homicides of female publicans/bar staff and 34 female caterers (Coggon et al., 2009). ${ }^{6}$ The researchers note the limitations of 
this study, including the fact that the death certificate records "the deceased person's last full-time job" (Coggon et al., 2009, p. 8), so we cannot know for sure if they were actively working in these jobs at the time of their death. Furthermore, we have no way of knowing if the victims' murders were examples of occupational homicide or whether they occurred under different circumstances. However, the study does tell us which occupational groups have disproportionality higher experiences of death by homicide.

Similarly, Brookman and Maguire (2003) note that between 1996 and 1999 the three jobs with the highest representation in the U.K. Homicide Index were security staff, medical staff, and social workers but again it is unknown whether these victims were killed in the course of work (p. 37). Unfortunately, there is no data source in the United Kingdom that records homicides occurring in the course of a victim's work. Despite the limitations of the data in the U.K. context, we attempt a tentative comparison below to establish whether sex work is the job with the highest risk of homicide among all others.

\section{Comparing Homicide Risk in Sex Work and Other Jobs}

If the estimated mortality rate by homicide for sex workers calculated by Potterat et al. (2004) is accepted then sex workers in the United States certainly do have the highest risk of homicide compared to any other job or profession. Can the same be said of the situation in the United Kingdom? Although we have an extensive record of sex workers murdered in the United Kingdom, we are unable to determine a mortality rate by homicide because to do so requires us to have a robust estimate of the total number of sex workers operating in the United Kingdom. This is notoriously difficult to do and previous attempts reached quite different conclusions. For instance, Kinnell (1999) using data from outreach projects estimated that there were 80,000 sex workers working in the United Kingdom and this number was used for many years as an approximation of the sex worker population. Sometime later, these numbers were queried and a reduced estimate of 35,870 was reached, using a different multiplier, but again based on data provided by sex work support projects (Cusick, Kinnell, Brooks-Gordon, \& Campbell, 2009). The complexities of mapping the sex industry, especially now that the Internet has moved the industry mostly online and advertisements for selling sex are prolific, continues to be documented and problematized (Sanders et al., 2018).

Even without estimated occupational homicide rates we have attempted a very general and tentative comparison between the numbers of sex worker homicides and the numbers of homicides by occupation reported in the ONS/HSE study. It must be stated that this comparison is being done based on all sex workers homicides (committed against cis-gendered female sex workers), work related and nonwork related, to match the data we have on other occupations, which does not distinguish between homicides occurring directly in the course of work. We believe that this still enables us to draw some preliminary conclusions with regard to the overall homicide risk of sex workers compared to those in other occupational groups. 
Table 2. Comparing Levels of Homicide by Occupational Group.

\begin{tabular}{lcc}
\hline & $\begin{array}{c}\text { Total number of homicides } \\
\text { recorded in occupational group } \\
\text { (work related and nonwork } \\
\text { related), I99I-2000 }\end{array}$ & $\begin{array}{c}\text { Available estimates on size of } \\
\text { occupational group }\end{array}$ \\
Occupational groups & 76 (NUM database) & 80,000 (I999) (Kinnell, I999) \\
\hline Female sex workers & 16 (Brookman \& Maguire, 2003) & $121,000$ (Apr-Jun 200I) (ONS $)$ \\
Female bar staff & 34 (Brookman \& Maguire, 2003) & 297,000 (Apr-Jun 200I) (ONSa) \\
\hline Female caterers ${ }^{b}$ & &
\end{tabular}

Note. NUM = National Ugly Mugs; ONS = Office for National Statistics.

${ }^{a}$ Estimates published annually by U.K. Office for National Statistics based on the Labor Force Survey. bCaterers as a job group is not used in the ONS statistics so we have used the data for occupational group "kitchen and catering assistants."

Table 2 shows the information we have available on the number of sex worker homicides compared to the occupations identified in the ONS/HSE study as having the highest proportionate mortality rates of homicide for women as well as estimates on the size of the occupational groups. ${ }^{7}$ We reiterate that this comparison is tentative and the estimation of the sex worker population is subject to all the caveats discussed above with regard to the challenges of mapping hard to reach groups. The figures do, however, suggest that sex workers are the group, compared to other occupational groups, with the greatest risk of homicide for women. Female sex workers were murdered in numbers 5 times greater than female bar staff (in the period 1991-2000) and the number of female sex workers (in 1999) was estimated to be well below the number of female bar staff around a similar time (2001). Female sex workers were killed twice as often as female caterers (in the period 1991-2000) even though there were potentially almost 4 times more women working as caterers than sex workers around the same time.

In addition to the tentative nature of this comparative assessment, it is also based on data that are almost 20 years old. It is difficult to know, without further research, whether the same results would be reached now based on more current data. It is worth noting that in the decade following the ONS/HSE study, the number of sex worker murders in the United Kingdom have fallen from a high of 95 homicides (93 ciswomen victims) in the period 2001 to 2010 to just 28 homicides (26 cis-women victims) between 2011 and 2016. We were unable to locate any more recent study on general occupational mortality or occupational homicide rates in the United Kingdom.

\section{Why Are Sex Workers Killed?}

We know the high levels of violence directed toward sex workers is a global epidemic (Deering et al., 2014). The motivations for murder against sex workers has been addressed but is largely the area given least attention in the literature. Brewer et al. (2006, p. 1106) note that sex worker homicides, especially those committed by "clients," "are not easily characterized by motives." They provide a long list of the various 
different motives cited in some of their data including "arguments over the sex for money/drugs exchange, responses to the victim's (attempted robbery) of the client, verbal insults from the victim, ... the client's misogyny, the client's hatred of prostitutes, the client's sadism ... " (Brewer et al., 2006). We know from the work of Kinnell (2006) that there are four key triggers to violence against sex workers from clients or those posing as clients: (a) refusing to perform certain sex acts, (b) disputes over money, (c) the sex act finishing before the man has reached orgasm, and (d) the client fails to get an erection. These have been highlighted as flash points which can result in serious violence.

Quinet (2011, p. 80) discusses some of the theories related to the high rate of murder experienced by sex workers including that "the prostitute's social status (or lack thereof) allows the offender to downplay the death and dehumanize the victim." She also argues that sex workers may be "more vulnerable to serial killers as members of a population of people referred to as the 'missing missing' - missing persons who were never reported as missing" (Quinet, 2011, p. 81). These factors are clearly evident in the words of Gary Ridgway, the Green River killer, who was convicted of 49 murders of women and girls, including sex workers, but is considered to be responsible for many more:

I picked prostitutes as my victims because I hate most prostitutes and did not want to pay them for sex. I also picked prostitutes as victims because they were easy to pick up without being noticed. I knew they would not be reported missing. I picked prostitutes because I thought I could kill as many of them as I wanted without getting caught. (State of Washington v Gary Leon Ridgway, 2003, p. 7, as quoted in Quinet, 2011, p. 81)

The targeting of sex workers by serial killers has also been highlighted in the case of Robert Pickton in BC, Canada, in the late 1990s and early 2000s. Responsible for at least 27 women murdered (many sex workers) and many more missing associated with Pickton, the vulnerability of sex workers has been a major cause for concern in this area (Jiwani \& Young, 2006). Understanding these crimes must go beyond the psychological profiling of perpetrators to look more deeply at the place of sex workers within the social conscience as well as the sex work legal frameworks that may increase vulnerability.

John Lowman's article (2000) about sex worker homicide in BC, Canada, is one of the few that engages more deeply with the question of why sex workers are so vulnerable to homicide. Lowman charts sharp increases in the numbers of sex workers murdered in BC from the beginning of the 1980s through to 1994, going from just three in the period 1975 to 1979 to 24 in 1990 to 1994 (pp. 990-991). In a more detailed analysis of 50 homicides between the period January 1982 to December 1994, it is clear that the trend observed in other studies and our database, in which the majority of homicide victims are street-based cis-gendered female sex workers, was also reflected in BC. Of the 50 cases analyzed, 48 of the victims were cis-gendered women and two were trans women (Lowman, 2000, p. 991). The vast majority being street-based sex workers with just two victims categorized as "escorts" and five as "exotic dancers" (Lowman, 2000). 
Making sense of this, Lowman's (2000, p. 988) hypothesis is that the proliferation of "discourses of disposal," which he describes as "media descriptions of the ongoing attempts of politicians, police, and resident's groups to 'get rid' of street prostitutes from residential areas" contributed to this increase in the murders of street sex workers. He documents a substantial increase in the number of articles focused on prostitution (from an average of 56 a year in 1980-1984 to an average of 124 from 1985-1990) in the main Vancouver-based newspapers (Lowman, 2000, p. 999). Lowman argues that from 1981 to 1985, there was a strong push from police, local authorities, and resident groups for new police powers to "sweep prostitution from the streets" (Lowman, 2000 , p. 1002). These campaigns led to the enacting of the communicating law in Canada, which made it an offense to communicate in a public place for the purposes of prostitution. He concludes,

It appears that the discourse on prostitution of the early 1980s was dominated by demands to get rid of prostitutes, creating a social milieu in which violence against prostitutes could flourish ... The association of this discourse of disposal to violence is clear enough. After 1985, the year in which the communicating law was enacted, there was a large increase in British Columbia of murders of women known to prostitute. (Lowman, 2000, p. 1003)

This analysis makes the connections between public discourses, media portrayal of sex workers, and legal frameworks and policing operations with an increase in homicides.

\section{Conclusion and Future Research Agenda}

The results of the literature review as well as the empirical analysis of the National Ugly Mug sex work murder database show that sex workers are, by a large margin, the occupational group at most risk of homicide in the United Kingdom and the United States. We hypothesize that the same trend applies in many other countries across the world. Existing studies have focused on the extent of sex worker homicide as well as trying to identify the personal characteristics that may make certain sex workers more vulnerable to homicide. In this article, we have called for future studies to acknowledge the difference between sex worker homicides occurring in the course of their work and those occurring in different circumstances to gather better knowledge on the occupational factors that may make sex workers so vulnerable to murder. Studies on wider occupational homicide have already concluded that factors such as working with the public, handling money, working alone at night or in isolated areas, and working in public places without access to control and security are all risk factors for elevated work-related homicide (Lavender, Ramirez-Irizarry, Bayakly, Koplan, \& Bryan, 2016; Loomis, Marshall, Wolf, Runyan, \& Butts, 2002; Loomis, Wolf, Runyan, Marshall, \& Butts, 2001). These risk factors are all applicable to sex work. Existing knowledge on occupational homicide and how to reduce vulnerability must be used in designing and implementing sex work policy, which, in our view, should always have sex worker safety as its primary consideration. 
Future research on sex worker homicide must also consider the social and legal contexts in which sex work takes place and how this may impact on vulnerability to homicide. Adopting simple safety strategies is often made impossible because of the criminal laws that exist against sex work in many jurisdictions. For example, brothel-keeping laws in the United Kingdom currently force indoor sex workers to work alone preventing them from working in pairs or groups. This is concerning in light of the fact that research shows the most effective strategy for reducing occupational homicide in the retail sector was ensuring that workers were not working alone at night (Loomis et al., 2002).

But perhaps most important of all is that work must be done to challenge and counter the pervasive stigma that exists against sex workers, making them so vulnerable to all forms of violence, including homicide (Lowman, 2000). Only with a combination of antistigma work alongside meaningful legal and policy change that prioritizes sex worker safety can there be any hope of addressing the tragedy of sex worker homicide.

\section{Acknowledgments}

We would like to thank the Wellcome Trust for this Seed Award funding.

\section{Declaration of Conflicting Interests}

The author(s) declared no potential conflicts of interest with respect to the research, authorship, and/or publication of this article.

\section{Funding}

The author(s) disclosed receipt of the following financial support for the research, authorship, and/or publication of this article: This research was funded by the Wellcome Trust Seed Award 201445/A116/2.

\section{Notes}

1. We use the term cis-gendered to refer to those who have the same gender identity as their assigned sex.

2. The Homicide Index is a government held index of information on homicides in England and Wales within the remit of the U.K. Home Office.

3. This cohort included every woman enrolled in the study but the mortality rates were calculated using a slightly reduced cumulative sample of 1,633 women for whom dates of first prostitution were observable (Potterat et al., 2004, p. 780). The moving cohort, for any given year, only included women who were within 3 years of first observable prostitution (Potterat et al., 2004, p. 780). This time period was chosen based on the researchers observations and it was felt that the "majority of living women in the cohort continued to work as prostitutes while in the moving cohort" (Potterat et al., 2004).

4. Hilary Kinnell was a founding member of the U.K. Network of Sex Work Projects in 2000 after working for several decades at a grassroots level with sex work projects and is author of Violence and Sex Work in Britain (2008).

5. These are the occupational categorizations used in the study. It is not clear why "taxicab drivers" and then "taxicab drivers and chauffeurs" are listed as two separate categories.

6. $95 \%$ confidence intervals are [110, 313] (bar staff) and [134, 270] (caterers) (Coggon, Harris, Brown, Rice, \& Palmer, 2009, p. 36). 
7. Data on size of occupational groups are recorded by the UK's Office for National Statistics, available at https://www.ons.gov.uk/employmentandlabourmarket/peopleinwork/ employmentandemployeetypes/datasets/employmentbyoccupationemp04

\section{References}

Bell, C. A. (1991). Female homicides in United States workplaces, 1980-1985. American Journal of Public Health, 81, 729-732.

Brents, B., Jackson, C., \& Hausbeck, K. (2010). The state of sex: Tourism, sex and sin in the New American Heartland. London, England: Routledge.

Brewer, D. D., Dudek, J. A., Potterat, J. J., Muth, S. Q., Roberts, J. M. Jr., \& Woodhouse, D. E. (2006). Extent, trends, and perpetrators of prostitution-related homicide in the United States. Journal of Forensic Sciences, 51, 1101-1108.

Brookman, F., \& Maguire, M. (2003). Reducing homicide: A review of the possibilities. Home Office Research, Development and Statistics Directorate. HMSO, London.

Coggon, D., Harris, E. C., Brown, T., Rice, S., \& Palmer, K. T. (2009). Occupational mortality in England and Wales, 1991-2000. London, England: Office of Public Sector Information.

Cusick, L., Kinnell, H., Brooks-Gordon, B., \& Campbell, R. (2009). Wild guesses and conflated meanings? Estimating the size of the sex worker population in Britain. Critical Social Policy, 29, 703-719.

Davis, H., Honchar, P. A., \& Suarez, L. (1987). Fatal occupational injuries of women, Texas 1975-84. American Journal of Public Health, 77, 1524-1527.

Deering, K. N., Amin, A., Shoveller, J., Nesbitt, A., Garcia-Moreno, C., Duff, P., . . Shannon, K. (2014). A systematic review of the correlates of violence against sex workers. American Journal of Public Health, 104(5), e42-e54.

Feis-Bryce, A. (2018). Policing sex work in Britain: A patchwork approach in Sanders. In T. Sanders \& M. Laing (Eds.), Policing the sex industry (pp. 19-38). London, England: Routledge.

Graham, L. (2017). Governing sex work through crime: Creating the context for violence and exploitation. The Journal of Criminal Law, 81, 201-216.

Heckathorn, D. D. (1997). Respondent-driven sampling: a new approach to the study of hidden populations. Social problems, 44(2), 174-199.

Hendricks, S. A., Jenkins, E. L., \& Anderson, K. R. (2007). Trends in workplace homicides in the U.S., 1993-2002: A decade of decline. American Journal of Industrial Medicine, 50, 316-325.

Jenkins, E. L. (1996). Homicide against women in the workplace. Journal of the American Medical Women's Association, 51, 118-122.

Jiwani, Y., \& Young, M. L. (2006). Missing and murdered women: Reproducing marginality in news discourse. Canadian Journal of Communication, 31.

Kinnell, H. (1999). Sex workers in England and Wales. Europap-UK Briefing Paper for Department of Health, National Sexual Health Strategy.

Kinnell, H. (2006). Murder made easy: The final solution to prostitution? In R. Campbell \& M. O'Neill (Eds.), Sex work now. Cullompton, UK: Willan.

Kinnell, H. (2008). Violence and sex work in Britain. Cullompton, UK: Willan.

Klambauer, E. (2017). Policing roulette: Sex workers'perception of encounters with police officers in the indoor and outdoor sector in England. Criminology \& Criminal Justice. Advance online publication. doi:10.1177/1748895817709865 
Lavender, A., Ramirez-Irizarry, V., Bayakly, A. R., Koplan, C., \& Bryan, J. M. (2016). Violent deaths among Georgia workers: An examination of suicides and homicides by occupation, 2006-2009. American Journal of Preventive Medicine, 51, S241-S250.

Levin, P. F., Hewitt, J. B., \& Misner, S. T. (1996). Workplace violence: Female occupational homicides in metropolitan Chicago. AAOHN Journal: Official Journal of the American Association of Occupational Health Nurses, 44, 326-331.

Loomis, D., Marshall, S. W., Wolf, S. H., Runyan, C. W., \& Butts, J. D. (2002). Effectiveness of safety measures recommended for prevention of workplace homicide. Journal of the American Medical Association, 287, 1011-1017.

Loomis, D., Wolf, S. H., Runyan, C. W., Marshall, S. W., \& Butts, J. D. (2001). Homicide on the job: Workplace and community determinants. American Journal of Epidemiology, 154, 410-417.

Lowman, J. (2000). Violence and the outlaw status of (street) prostitution in Canada. Violence Against Women, 6, 987-1011.

Lowman, J., \& Fraser, L. (1994). Violence against persons who prostitute: The experience in British Columbia. Retrieved from http://publications.gc.ca/collections/collection_2014/jus/ J3-7-1996-14-eng.pdf

Mai, N. (2009). Migrant workers in the UK sex industry: Final policy-relevant report. London, England: Economic and Social Research Council (ESRC).

Magnani, R., Sabin, K., Saidel, T., \& Heckathorn, D. (2005). Review of sampling hard-to-reach and hidden populations for HIV surveillance. Aids, 19, S67-S72.

Neville, L. (2012). Exploring fatal and non-fatal attacks on prostitutes: An action systems approach (Doctoral thesis, University of Surrey, Guildford, UK).

Potterat, J. J., Brewer, D. D., Muth, S. Q., Rothenberg, R. B., Woodhouse, D. E., Muth, J. B., ... Brody, S. (2004). Mortality in a long-term open cohort of prostitute women. American Journal of Epidemiology, 159, 778-785.

Quinet, K. (2011). Prostitutes as victims of serial homicide: Trends and case characteristics, 1970-2009. Homicide Studies, 15, 74-100.

Salfati, C. G., James, A. R., \& Ferguson, L. (2008). Prostitute homicides: A descriptive study. Journal of Interpersonal Violence, 23, 505-543.

Sanders, T., \& Laing, M. (Eds). (2018) Policing the sex industry: Protectionism, paternalism and politics, London, England: Routledge.

Sanders, T., Scoular, J., Campbell, R., Pitcher, J., \& Cunningham, S. (2018). Internet sex work: Beyond the gaze. London, England: Palgrave Macmillan.

Tiesman, H. M., Gurka, K. K., Konda, S., Coben, J. H., \& Amandus, H. E. (2012). Workplace homicides among U.S. women: The role of intimate partner violence. Annals of Epidemiology, 22, 277-284.

Ward, H., Day, S., \& Weber, J. (1999). Risky business: Health and safety in the sex industry over a 9 year period. Sexually Transmitted Infections, 75, 340-343.

\section{Author Biographies}

Stewart Cunningham is a $\mathrm{PhD}$ student at the University of Strathclyde, a freelance researcher and activist. His research and activist interests are focused on sex work legal frameworks and the political discourse used in campaigning for sex work law reform.

Lucy Platt is a public health epidemiologist working examining how social and health policies and interventions influence people who sell sex and/or inject drugs' vulnerability to 
blood-borne viruses, sexually transmitted infections (STI) and other health harms. Much of this work has focused on the UK, Russian Federation, Eastern Europe and East Africa.

Teela Sanders is Professor of Criminology at the University of Leicester, where she works on understanding the intersections between gender, crime and regulation. Her work sits broadly in the area of the sex industry where she has published extensive books and articles.

Pippa Grenfell has worked at LSHTM since 2007 examining how social, cultural, economic, political and legal contexts shape the safety, health and rights of marginalised groups and communities, particularly sex workers.

P.G Macioti is a researcher in the fields of migration, citizenship, sex work and language. She completed her $\mathrm{PhD}$ in Politics and International Studies at the Open University in 2014. Her $\mathrm{PhD}$ was about language, transformation and the enactment of citizenship by marginalised groups, including migrant sex workers and is now working on a study SexHum: Migration, sex work and trafficking. 